\title{
Comparative Efficacy of Two Microdoses of a Potentized Homeopathic Drug, Arsenicum Album, to Ameliorate Toxicity Induced by Repeated Sublethal Injections of Arsenic Trioxide in Mice
}

\author{
Pathikrit Banerjee $^{\text {a }}$ Soumya Sundar Bhattacharyya ${ }^{a}$ Surajit Pathak ${ }^{a}$ \\ Boujedaini Naoual $^{b}$ Philippe Belon ${ }^{b}$ Anisur Rahman Khuda-Bukhsh ${ }^{a}$ \\ ${ }^{a}$ Cytogenetics and Molecular Biology Laboratory, Department of Zoology, University of Kalyani, Kalyani, India; \\ ${ }^{b}$ Boiron Lab, Sainte-Foy-lès-Lyon, France
}

\section{Key Words}

Arsenic toxicity $\cdot$ Mice $\cdot$ Biomarkers $\cdot$ Homeopathy $\cdot$

Matrix metalloproteinase

\begin{abstract}
Objectives: To evaluate the efficacy of 2 potentized homeopathic remedies of Arsenicum Album (Ars Alb) $-6 \mathrm{C}$ and $30 \mathrm{C}$ - in combating chronic arsenic toxicity induced by repeated sublethal injections in mice (Mus musculus). Methods: Mice were randomized and divided into sets: (1) normal (control 1); (2) normal + succussed alcohol (control 2); (3) $\mathrm{As}_{2} \mathrm{O}_{3}(0.016 \%)$ injected at $1 \mathrm{ml} / 100 \mathrm{~g}$ body weight every 7 days (treated); (4) $\mathrm{As}_{2} \mathrm{O}_{3}$ injected + succussed alcohol (positive control); (5) $\mathrm{As}_{2} \mathrm{O}_{3}$ injected + Ars Alb 6C (drug-fed); (6) $\mathrm{As}_{2} \mathrm{O}_{3}$ injected + Ars Alb $30 \mathrm{C}$ (drug-fed). Cytogenetical endpoints like chromosome aberrations, micronuclei, mitotic index, sperm head abnormality and biochemical protocols like acid and alkaline phosphatases, aspartate and alanine aminotransferases, reduced glutathione, lipid peroxidation, catalase and succinate dehydrogenase were studied at 30,60, 90 and 120 days. Results: Compared to controls, chromosome aberrations, micronuclei, sperm head abnormality frequencies and activities of acid and alkaline phosphatases, aspartate and alanine aminotransferases and lipid peroxi-
\end{abstract}

dation were reduced in both drug-fed series, while mitotic index and activities of glutathione, catalase and succinate dehydrogenase were increased. Ars Alb $30 \mathrm{C}$ showed marginally better efficacy than Ars Alb 6C. Conclusion: Both remedies indicated potentials of use against arsenic intoxication.

Copyright $\odot 2008$ S. Karger AG, Basel

\section{Introduction}

In recent times, arsenic has proved to be one of the most important toxicants, causing tremendous health hazards to large populations in some 20 countries, including large areas of West Bengal and Bangladesh, mainly through contaminated drinking water. Arsenic exposure has been linked to cardiovascular disease and diabetes. In epidemiological studies in Bangladesh, where large-scale arsenic toxicity has been reported as a result of groundwater contamination, hypertension is recorded as of most common occurrence [1]. Exposure to $20 \mathrm{ppb}$ or more in drinking water has also been associated with increased mortality from cardiovascular diseases [2]. Further, cumulative arsenic exposure has been positively associated with the incidence of type II diabetes in Tai-

\section{KARGER}

Fax +4161306 1234

E-Mail karger@karger.ch

www.karger.com (c) $2008 \mathrm{~S}$. Karger AG, Basel

1015-2008/08/0753-0156\$24.50/0

Accessible online at:

www.karger.com/pat
Anisur R. Khuda-Bukhsh

Department of Zoology, University of Kalyani

Kalyani, West Bengal 741235 (India)

Tel. +91 332582 8768, Fax +91 332582 8282,E-Mail prof_arkb@yahoo.co.in 
wan, another area where arsenic contamination of water is common. Apart from these, chronic exposure to arsenic has also been implicated in anemia, peripheral neuropathy, liver and kidney damage and irritation of the skin and mucous membranes. Peripheral vascular disease is also common in chronically exposed individuals [3]. Chronic inhalation of inorganic arsenic has been shown to be associated with the risk of human lung cancer [4]. Arsenic exposure has also been linked to hepatocellular carcinoma, carcinoma, cirrhosis and hepatoportal sclerosis [5]. Besides, chronic arsenic intoxication may present as diffuse symptoms: headache, fatigue, confusion, polyneuritis with distal weakness, exfoliative dermatitis, hyperkeratosis, hyperpigmentation and Mees' lines. Long-term administration of inorganic arsenic has produced liver lesions, anemia and pathological skin changes in animal models [6]. Clastogenic activity has been consistently demonstrated in vivo when inorganic arsenic compounds have been investigated in the bone marrow of mice [7]. Arsenic trioxide has induced low incidences of carcinomas, adenomas, papillomas and adenomatoid lesions of the respiratory tract in hamsters after intratracheal instillation. A high incidence of lung carcinomas was induced in rats following a single intratracheal instillation of a pesticide mixture containing calcium arsenate. Intratracheal instillations of calcium arsenate into hamsters resulted in a borderline increase in the incidence of lung adenomas, while no such effect was observed with arsenic trisulfide. Sodium arsenite enhanced the incidence of renal tumors induced in rats by intraperitoneal injection of N-nitrosodiethylamine [8]. Administration of high doses of inorganic arsenic by oral, intraperitoneal or intravenous routes may cause embryo lethality, increased resorptions or fetal malformations in laboratory animals [7]. The major teratogenic effects induced by inorganic arsenic in laboratory animals are neural tube defects. The malformations seen are dependent on the dose of arsenic administered as well as the gestational age. A study in mice orally intoxicated with arsenic, however, found no significant impact on their reproductive success. Yet, a slightly altered male:female ratio and a slight trend towards a smaller number of pups per litter were noted [9].

Arsenic is found in food, soil, water and airborne particles as a result of both natural and human activities [10]. More than $80 \%$ of arsenic compounds are used to manufacture products with agricultural applications such as insecticides, herbicides, fungicides, algicides, sheep dips, wood preservatives, dye stuffs and medicines [11]. Inorganic arsenic is more toxic in nature and has been classi- fied by the International Agency for Research on Cancer (IARC) as a group 1 carcinogen [12].

A series of our earlier studies [13-18] highlighted the ameliorative potentials of a potentized homeopathic drug, Arsenicum Album (Ars Alb) 30C at different fixation intervals against a single dose of injection of arsenic trioxide. However, the efficacy against repeated injections of $\mathrm{As}_{2} \mathrm{O}_{3}$, which produce more pronounced effect, was not studied earlier. The present investigation was therefore carried out to ascertain the comparative efficacies of $2 \mathrm{mi}-$ crodoses of Ars Alb, namely 6C and 30C, in ameliorating toxicity inflicted by repeated sublethal injections of arsenic trioxide, simulating a chronic condition of exposure.

\section{Materials and Methods}

\section{Animals}

Swiss albino mice, Mus musculus, reared in the Animal Facility House of the Department of Zoology, Kalyani University, under the supervision of the Animal Welfare Committee, University of Kalyani, were used for all in vivo experiments with prior approval of the Institutional Animal Ethics Committee. Mice were provided normal low-protein diet made of wheat, flour and powdered milk without any other animal protein supplementation and water ad libitum.

Mice were randomized and a group of 30 healthy mice of both sexes, weighing between 25 and $30 \mathrm{~g}$, were used for each fixation interval. Each group of 30 mice was divided further into 5 sets of 6 mice each.

\section{Experimental Protocol: Control Series}

\section{Negative Control}

This group of healthy normal mice was maintained on normal low-protein diet, but was not treated with arsenic.

\section{Alcohol Control}

The vehicle of the homeopathic remedies being ethyl alcohol, a group of healthy mice were fed diluted succussed alcohol (to minimize lives of mice only succussed Alc 30 was used as a common control, since no significant difference in results was obtained in all previous studies in this laboratory between Alc 6 and Alc 30) along with normal low-protein diet.

\section{Positive Control}

$\mathrm{As}_{2} \mathrm{O}_{3}$-Treated plus Succussed Alcohol-Fed Groups. This group of normal low-protein diet-fed mice was injected $0.016 \% \mathrm{As}_{2} \mathrm{O}_{3}$ and fed Alc 30, till they were sacrificed, to learn about modulated effect, if any, produced by ethyl alcohol on arsenic-intoxicated mice.

Arsenic-Intoxicated Group: $\mathrm{As}_{2} \mathrm{O}_{3}$-Treated Group. This group of low-protein diet-fed mice was injected $0.016 \% \mathrm{As}_{2} \mathrm{O}_{3}$ solution at $1 \mathrm{ml} / 100 \mathrm{~g}$ body weight at an interval of 7 days till sacrificed. 
Arsenic-Intoxicated Drug-Fed Groups: $\mathrm{As}_{2} \mathrm{O}_{3}$-Treated DrugFed Groups. This group of low-protein diet-fed mice was injected $0.016 \% \mathrm{As}_{2} \mathrm{O}_{3}$ solution and fed with either of the potentized homeopathic drugs - Ars Alb 6C (3 times daily) and Ars Alb 30C (twice daily) - till sacrificed.

\section{Drug Preparation}

The potentized form of the homeopathic drug, Ars Alb 6C and Ars Alb 30C, and the placebo (Alc 30 in this case, derived by the same homeopathic dilution and succussion procedure, but without arsenic trioxide as the starting material used in case of preparation of the homeopathic remedies), were obtained by the use of standard procedure. These were procured from Boiron Lab, Lyon, France, as gift. During potentization of the homeopathic remedies, $1 \mathrm{ml}$ of original (1\%) metallic salt solution prepared from Analytical Reagent quality arsenic trioxide (powder) dissolved in a mixture of glycerine and $70 \%$ alcohol is diluted with $99 \mathrm{ml}$ of $70 \%$ ethyl alcohol approximately and given 10 machine-operated, moderate, equal and successive jerks to produce the potency 1 . Similarly, $1 \mathrm{ml}$ of the drug solution at potency 1 is again added with $99 \mathrm{ml}$ of $70 \%$ ethanol and 10 jerks are given to produce potency 2 and in this way by successive potentization, the 6 th and 30th potencies of Ars Alb (Ars Alb 6C and Ars Alb 30C, respectively) were produced (centesimal dilution). Similarly, alcohol (Alc 30) was potentized from $70 \%$ ethyl alcohol by successive jerks and dilution procedure. One milliliter each of Ars Alb 6C and Ars Alb 30C was diluted separately with $20 \mathrm{ml}$ of double-distilled water to make the stock solution of Ars Alb 6C and Ars Alb 30C. In the same way, the stock solution of succussed alcohol was made. To minimize lives of mice, only succussed Alc 30 was used as a common control, since no significant differences in results were obtained in all previous studies in this laboratory between Alc 6 and Alc 30.

\section{Feeding Procedure and Dosage}

Each mouse was orally fed 1 drop $(0.06 \mathrm{ml})$ of stock solution of Ars Alb 6C (three times daily) or Ars Alb 30C or Alc 30 (twice daily), as the case may be, through gavage with the aid of a fine pipette.

\section{Laboratory Methodology}

\section{Cytogenetical Assay}

The standard cytogenetical protocols, like assays of chromosome aberrations (CA), micronuclei $(\mathrm{MN})$, mitotic index (MI) and sperm head anomaly (SHA), have been adopted in the present study for testing genotoxicity $[19,20]$. A total of 300 bone marrow cells were observed for CA, 3,000 for MN, 5,000 cells for MI and 5,000 sperms for SHA analysis.

\section{Biochemical Assays}

Preparation of Tissue Extracts. Mice were killed by cervical dislocation and their liver and spleen tissues were excised and placed in an ice bath. Approximately equal amounts of liver and spleen tissues were homogenized separately and diluted in phosphate buffer saline followed by centrifugation at 3,000 $\mathrm{g}$ for 20 min in a cooling centrifuge (C24; Remi Instruments, Mumbai, India). The supernatant from each homogenate was used as aliquot. For the study of aspartate and alanine amino transferases (AST and ALT, respectively), acid and alkaline phosphatases (AcP and AlkP, respectively), lipid peroxidation (LPO), reduced glutathione (GSH) content, catalase (CAT) and succinate dehydrogenase (SDH), standard methods [19-21] were adopted.

\section{Pathological Parameters}

Estimation of Blood Glucose Level. Blood glucose content was assayed by the GOD-POD Endpoint Colorimetric assay kit supplied by Span Diagnostics Limited, Baroda, India.

Determination of Hemoglobin Content. Hemoglobin content was determined according to the manufacturer's protocol (Span Diagnostics Limited) with the help of a hemometer (Marienfeld, Lauda-Königshofen, Germany).

Serum Hormone Assays. Serum estradiol and testosterone contents were assayed by using the appropriate diagnostic kit (EQUIPAR srl, Saronno, Italy) with the aid of an ELISA reader (Eldex 3.8; Eldex Laboratories, Napa, Calif., USA) at $450 \mathrm{~nm}$.

Matrix Metalloproteinase Activity. For the study of matrix metalloproteinase (MMP) activity, the method of Billings et al. [22] was adopted.

Determination of Elemental Arsenic Content. The arsenic contents in liver and spleen tissues were measured by the standardized atomic absorption spectrometry [23, 24].

\section{Statistical Analysis and Scoring of Data}

Statistical significance of the difference between experimental groups was calculated using Student's paired t test for 2 means [25] and one-way ANOVA (SPSS 10.0; SPSS Inc., Chicago, Ill., USA). $\mathrm{p}<0.05$ was considered significant.

\section{Results}

\section{Cytogenetical Studies}

\section{Chromosome Aberrations}

Compared with normal chromosomes in metaphase plate (fig. 1a), several types of CA of both major and minor types were observed in certain plates of $\mathrm{As}_{2} \mathrm{O}_{3}$ - and $\mathrm{As}_{2} \mathrm{O}_{3}+$ alcohol-fed mice (fig. 1b-d; fig. 2). The reduction in frequencies of total aberrations in both Ars Alb 6Cand Ars Alb 30C-fed series was significant at 120 days $(\mathrm{p}<0.001)$. Ars Alb 30C appeared to show a greater magnitude of protective ability, particularly at longer fixation intervals.

\section{Sperm Head Anomaly}

Sperms showing abnormal head morphology (fig. 1eg) were greater in number in different arsenic treatment series (fig. 3). The frequencies of SHA were considerably 
decreased in both Ars Alb 30C- and Ars Alb 6C-fed series, the differences with regard to controls were statistically significant at all fixation intervals except at day 60 for Ars Alb 6C. Though Ars Alb 30C and Ars Alb 6C showed very close protective effects at all fixation intervals except at day 30, the efficacy of Ars Alb 30C and Ars Alb 6 by Ars Alb $6 \mathrm{C}$ appeared to be a little better than that of Ars Alb 6.

\section{Mitotic Index}

There was a gradual reduction in the frequencies of MI in the arsenic trioxide-injected group (fig. 4). In Ars Alb 30C-fed series, there was an increase in MI frequency at all fixation intervals, while in Ars Alb 6C-treated series the increase in MI frequency was statistically significant only at days 90 and 120 .

\section{Micronucleated Erythrocytes}

The highest percentages of MN (fig. $1 \mathrm{~h}-\mathrm{i}$ ) were noticed in $\mathrm{As}_{2} \mathrm{O}_{3}+$ alcohol-fed mice at all fixation intervals. In both Ars Alb 6C-and Ars Alb 30C-fed mice there was a gradual reduction in $\mathrm{MN}$ at successive intervals of fixation, except at day 60 . The magnitude of protection rendered by Ars Alb 6C was better than Ars Alb 30C at days 60 and 90 , while very close effects were obtained for both Ars Alb 6C and Ars Alb 30C at days 30 and 120 (fig. 5).

\section{Biochemical Changes}

\section{AcP and AlkP Activities}

The AcP activity in $\mathrm{As}_{2} \mathrm{O}_{3}+$ alcohol-fed series was significantly increased in both liver and spleen tissues at all fixation intervals when compared with normal controls (table 1). Decrease in liver AcP activity of $\mathrm{As}_{2} \mathrm{O}_{3}+\mathrm{Ars} \mathrm{Alb}$ $30 \mathrm{C}$-fed mice was at a higher scale $(\mathrm{p}<0.0001)$ than that for the $\mathrm{As}_{2} \mathrm{O}_{3}+$ Ars Alb 6C-treated group ( $p<0.01$ to $p<0.001)$ except at day 90. In the spleen tissues of both drug-fed groups there was a slight increase in AcP activity at day 90, which again decreased at day 120 .

The AlkP activity in $\mathrm{As}_{2} \mathrm{O}_{3}+$ alcohol-fed series was notably increased in both liver and spleen tissues at all fixation intervals when compared with normal controls (table 1). In the liver tissue of $\mathrm{As}_{2} \mathrm{O}_{3}+\mathrm{Ars} \mathrm{Alb} 6 \mathrm{C}$-treated and $\mathrm{As}_{2} \mathrm{O}_{3}+\mathrm{Ars}$ Alb 30C-treated groups a minor wave of increase and decrease in the activity of AlkP was observed at day 90 and 60 , respectively. In the spleen tissue of $\mathrm{As}_{2} \mathrm{O}_{3}+$ Ars Alb 30C-fed mice, a slight increase in AlkP activity was observed at day 60 which again decreased at day 90 and 120, unlike that of Ars Alb 6C,

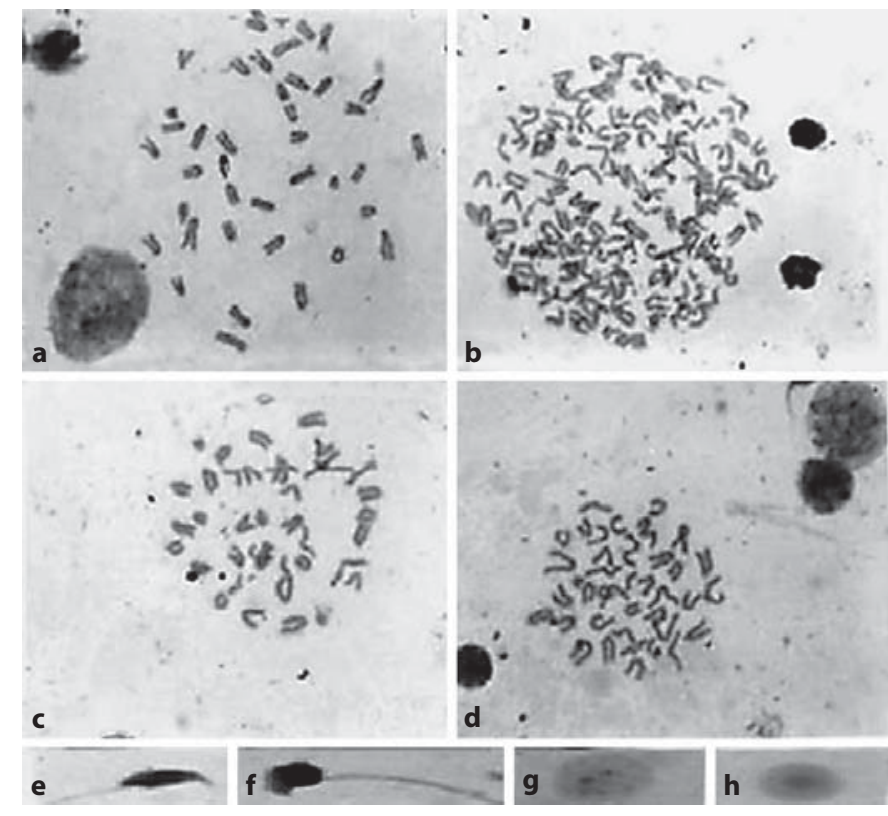

Fig. 1. Photomicrographs of metaphase complements. a Typical normal spread. b Polyploidy. c Precocious centromeric separation. d Translocation. e Sperm with normal head shape. $\mathbf{f}, \mathbf{g}$ Sperm with abnormal head shapes. h Polychromatic erythrocyte showing micronucleus.

where the activity gradually decreased at all fixation intervals $(\mathrm{p}<0.05$ to $\mathrm{p}<0.01)$.

\section{Lipid Peroxidation}

LPO activity (table 1 ) was significantly decreased in Ars Alb 30C-fed ( $<<0.05$ to $p<0.001)$ and Ars Alb 6Cfed ( $p<0.05$ to $p<0.01$ ) groups of mice when compared with arsenic trioxide-treated series at all fixation intervals in both tissues. The protection rendered by Ars Alb $30 \mathrm{C}$ appeared to be greater than that for Ars Alb 6C.

\section{AST and ALT Activities}

The AST activities in $\mathrm{As}_{2} \mathrm{O}_{3}+$ alcohol-treated mice were appreciably enhanced at all fixation intervals in liver and spleen compared to normal controls (table 2). The decrease in AST activities in the liver of $\mathrm{As}_{2} \mathrm{O}_{3}+\mathrm{Ars} \mathrm{Alb}$ $30 \mathrm{C}$-fed mice was more appreciable at all fixation intervals $(\mathrm{p}<0.05$ to $\mathrm{p}<0.001)$ than that of the $\mathrm{As}_{2} \mathrm{O}_{3}+\mathrm{Ars}$ Alb 6C-fed group. But in spleen of $\mathrm{As}_{2} \mathrm{O}_{3}+$ Ars Alb 6Cfed mice, a slight increase in AST activity was observed at day 90, which again decreased at day 120 , the increase and decrease both being statistically significant.

The decrease in ALT activities (table 2) in liver of $\mathrm{As}_{2} \mathrm{O}_{3}+$ Ars Alb 30C-fed mice was slightly better than 
Fig. 2. Column plot showing CA in different series of mice at different fixation intervals. ${ }^{*} \mathrm{p}<0.05 ;{ }^{* *} \mathrm{p}<0.01 ;{ }^{* * *} \mathrm{p}<$ 0.001 .

Fig. 3. Column plot showing SHA in different series of mice at different fixation intervals. ${ }^{*} \mathrm{p}<0.05 ;{ }^{* *} \mathrm{p}<0.01 ;{ }^{* *} \mathrm{p}<$ 0.001 .

Fig. 4. Column plot showing MI in different series of mice at different fixation intervals. ${ }^{* *} \mathrm{p}<0.01 ;{ }^{* * *} \mathrm{p}<0.001$.
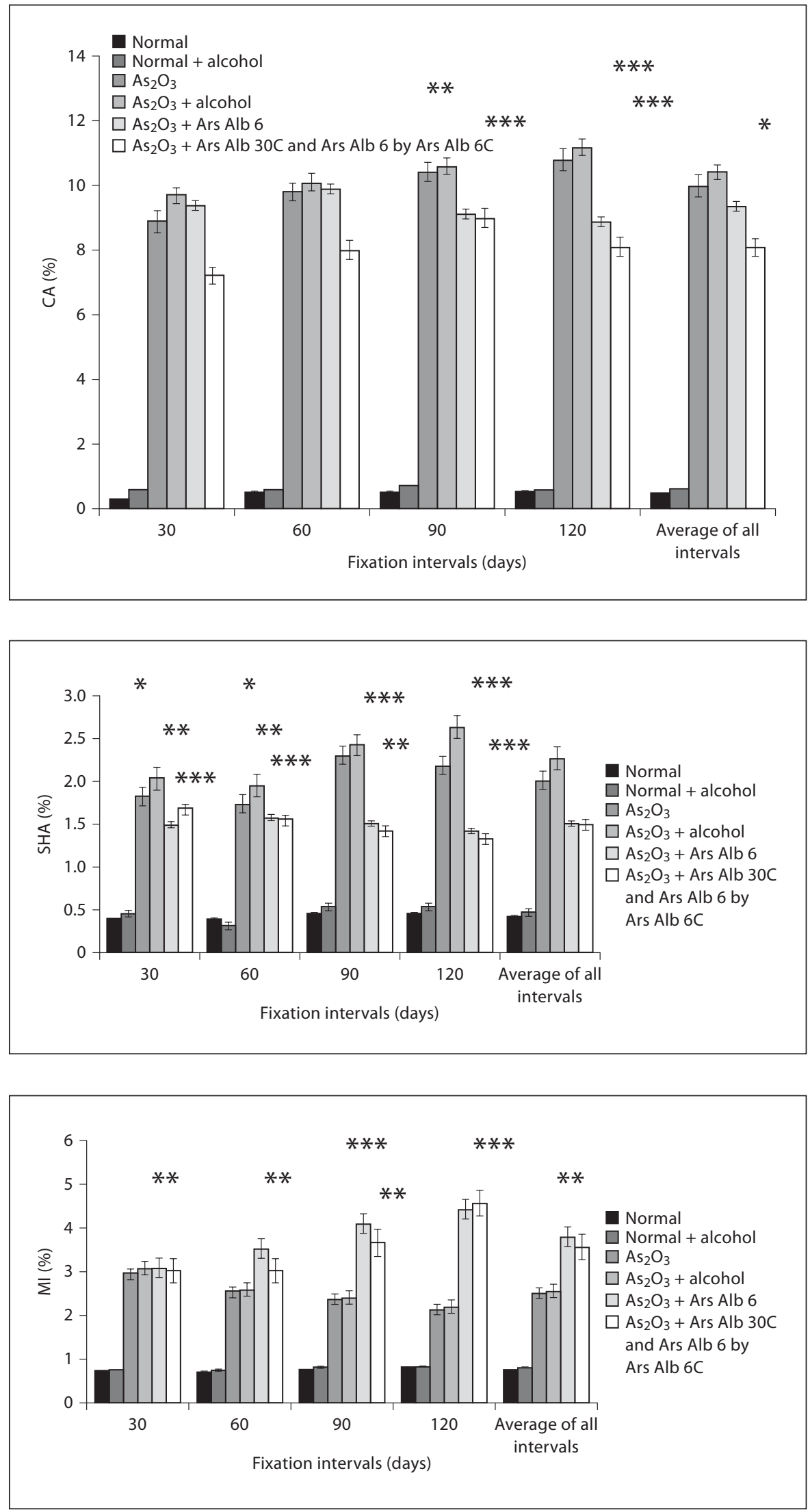
Fig. 5. Column plot showing $\mathrm{MN}$ in different series of mice at different fixation intervals. ${ }^{*} \mathrm{p}<0.05 ;{ }^{* *} \mathrm{p}<0.01 ;{ }^{* * *} \mathrm{p}<$ 0.001 .

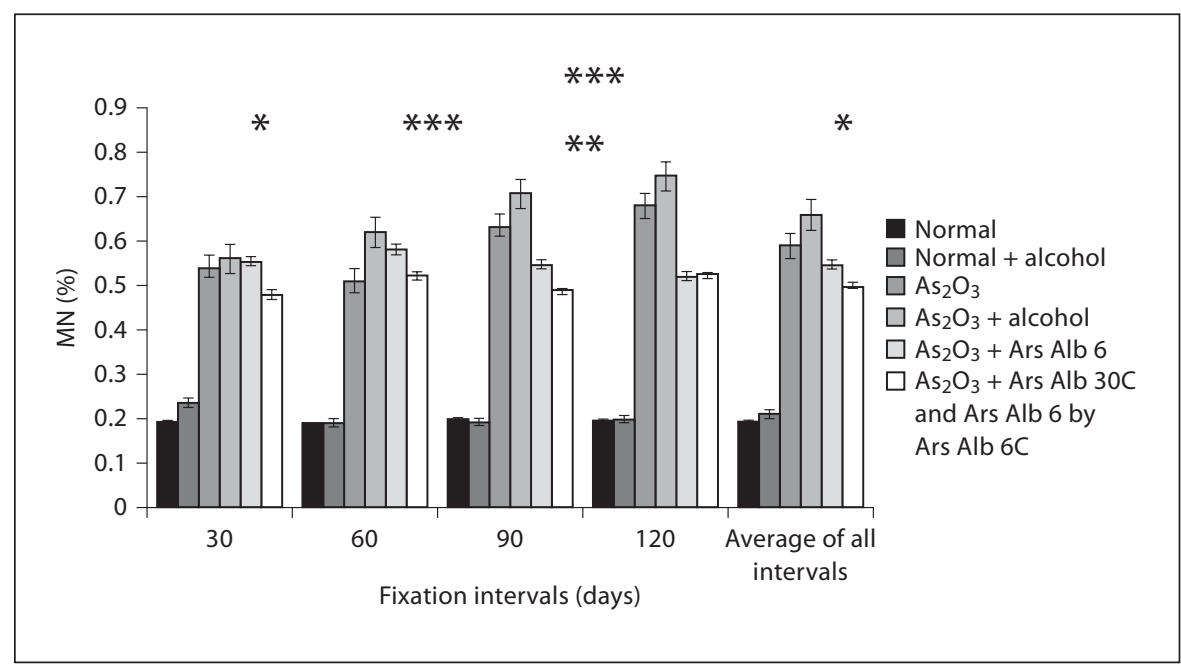

Table 1. Mean activities of AcP, AlkP and LPO in liver and spleen of mice treated with $\mathrm{As}_{2} \mathrm{O}_{3}, \mathrm{As}_{2} \mathrm{O}_{3}+$ alcohol, $\mathrm{As} \mathrm{O}_{3}+\mathrm{Ars} \mathrm{Alb} 6$, $\mathrm{As}_{2} \mathrm{O}_{3}+$ Ars Alb 30C and $\mathrm{As}_{2} \mathrm{O}_{3}+$ Ars Alb 6 by $\mathrm{As}_{2} \mathrm{O}_{3}+$ Ars Alb 6C and their normal positive and normal + alcohol negative controls

\begin{tabular}{|c|c|c|c|c|c|c|c|c|c|c|c|c|c|}
\hline \multirow{3}{*}{$\begin{array}{l}\text { FI } \\
\text { days }\end{array}$} & \multirow[t]{3}{*}{ Series } & \multicolumn{4}{|c|}{$\mathrm{AcP}, \mathrm{nM} / 100 \mathrm{mg}$ protein/min } & \multicolumn{4}{|c|}{ AlkP, nM/100 mg protein/min } & \multicolumn{4}{|c|}{ LPO, nM/MDA/mg wet tissue } \\
\hline & & \multicolumn{2}{|l|}{ liver } & \multicolumn{2}{|l|}{ spleen } & \multicolumn{2}{|l|}{ liver } & \multicolumn{2}{|l|}{ spleen } & \multicolumn{2}{|l|}{ liver } & \multicolumn{2}{|l|}{ spleen } \\
\hline & & activity $\pm S E$ & prot. & activity $\pm \mathrm{SE}$ & prot. & activity $\pm \mathrm{SE}$ & prot. & activity $\pm \mathrm{SE}$ & prot. & activity $\pm \mathrm{SE}$ & prot. & activity $\pm \mathrm{SE}$ & prot. \\
\hline \multirow[t]{6}{*}{30} & normal & $0.041 \pm 0.003$ & & $0.03 \pm 0.001$ & & $0.018 \pm 0.001$ & & $0.025 \pm 0.002$ & & $0.089 \pm 0.02$ & & $0.17 \pm 0.002$ & \\
\hline & normal + alcohol & $0.034 \pm 0.005$ & & $0.036 \pm 0.002$ & $\mathrm{a}$ & $0.037 \pm 0.001$ & c & $0.031 \pm 0.001$ & $\mathrm{a}$ & $0.094 \pm 0.003$ & & $0.185 \pm 0.003$ & $\mathrm{~b}$ \\
\hline & $\mathrm{As}_{2} \mathrm{O}_{3}$ & $0.076 \pm 0.001$ & & $0.074 \pm 0.001$ & & $0.031 \pm 0.002$ & & $0.03 \pm 0.001$ & & $0.262 \pm 0.013$ & & $0.242 \pm 0.041$ & \\
\hline & $\mathrm{As}_{2} \mathrm{O}_{3}+$ alcohol & $0.085 \pm 0.001$ & $c$ & $0.076 \pm 0.002$ & & $0.035 \pm 0.003$ & & $0.037 \pm 0.002$ & $\mathrm{a}$ & $0.281 \pm 0.010$ & & $0.262 \pm 0.040$ & \\
\hline & $\mathrm{As}_{2} \mathrm{O}_{3}+$ Ars Alb 6C & $0.079 \pm 0.001$ & $\mathrm{~b}$ & $0.053 \pm 0.002$ & $c$ & $0.03 \pm 0.001$ & & $0.035 \pm 0.002$ & & $0.285 \pm 0.014$ & & $0.326 \pm 0.029$ & \\
\hline & $\mathrm{As}_{2} \mathrm{O}_{3}+\mathrm{Ars} \mathrm{Alb} 30 \mathrm{C}$ & $0.076 \pm 0.001$ & $\mathrm{~b}$ & $0.064 \pm 0.002$ & $\mathrm{~b}$ & $0.022 \pm 0.001$ & $\mathrm{~b}$ & $0.033 \pm 0.002$ & & $0.228 \pm 0.019$ & $\mathrm{a}$ & $0.246 \pm 0.013$ & \\
\hline \multirow[t]{6}{*}{60} & normal & $0.047 \pm 0.001$ & & $0.021 \pm 0.003$ & & $0.012 \pm 0.001$ & & $0.022 \pm 0.003$ & & $0.05 \pm 0.002$ & & $0.105 \pm 0.02$ & \\
\hline & normal + alcohol & $0.046 \pm 0.002$ & & $0.022 \pm 0.005$ & & $0.013 \pm 0.002$ & & $0.026 \pm 0.002$ & & $0.056 \pm 0.005$ & & $0.087 \pm 0.004$ & \\
\hline & $\mathrm{As}_{2} \mathrm{O}_{3}$ & $0.086 \pm 0.003$ & & $0.077 \pm 0.003$ & & $0.035 \pm 0$ & & $0.034 \pm 0.004$ & & $0.277 \pm 0.031$ & & $0.272 \pm 0.028$ & \\
\hline & $\mathrm{As}_{2} \mathrm{O}_{3}+$ alcohol & $0.090 \pm 0.001$ & & $0.086 \pm 0.004$ & & $0.039 \pm 0.006$ & & $0.038 \pm 0.002$ & & $0.246 \pm 0.028$ & & $0.278 \pm 0.006$ & \\
\hline & $\mathrm{As}_{2} \mathrm{O}_{3}+$ Ars Alb 6C & $0.071 \pm 0$ & $\mathrm{c}$ & $0.052 \pm 0.003$ & c & $0.026 \pm 0$ & & $0.031 \pm 0.003$ & & $0.236 \pm 0.025$ & & $0.251 \pm 0.022$ & \\
\hline & $\mathrm{As}_{2} \mathrm{O}_{3}+$ Ars Alb $30 \mathrm{C}$ & $0.07 \pm 0$ & c & $0.059 \pm 0.003$ & c & $0.026 \pm 0.003$ & & $0.034 \pm 0.002$ & & $0.139 \pm 0.012$ & $\mathrm{~b}$ & $0.219 \pm 0.020$ & $\mathrm{a}$ \\
\hline \multirow[t]{6}{*}{90} & normal & $0.01 \pm 0$ & & $0.035 \pm 0$ & & $0.018 \pm 0.001$ & & $0.012 \pm 0.001$ & & $0.04 \pm 0.001$ & & $0.105 \pm 0.002$ & \\
\hline & normal + alcohol & $0.031 \pm 0.003$ & & $0.031 \pm 0.008$ & $c$ & $0.024 \pm 0.002$ & $\mathrm{a}$ & $0.021 \pm 0.001$ & $\mathrm{c}$ & $0.094 \pm 0.002$ & $c$ & $0.118 \pm 0.003$ & $\mathrm{~b}$ \\
\hline & $\mathrm{As}_{2} \mathrm{O}_{3}$ & $0.054 \pm 0.003$ & & $0.085 \pm 0.001$ & & $0.036 \pm 0.002$ & & $0.043 \pm 0.002$ & & $0.292 \pm 0.025$ & & $0.282 \pm 0.002$ & \\
\hline & $\mathrm{As}_{2} \mathrm{O}_{3}+$ alcohol & $0.057 \pm 0.003$ & & $0.089 \pm 0.005$ & & $0.041 \pm 0.001$ & & $0.045 \pm 0.001$ & & $0.298 \pm 0.003$ & & $0.293 \pm 0.023$ & \\
\hline & $\mathrm{As}_{2} \mathrm{O}_{3}+$ Ars Alb 6C & $0.053 \pm 0.002$ & & $0.075 \pm 0.008$ & & $0.029 \pm 0.001$ & c & $0.028 \pm 0.005$ & $\mathrm{a}$ & $0.183 \pm 0.031$ & $\mathrm{~b}$ & $0.203 \pm 0.026$ & $\mathrm{a}$ \\
\hline & $\mathrm{As}_{2} \mathrm{O}_{3}+$ Ars Alb 30C & $0.051 \pm 0.004$ & & $0.067 \pm 0.005$ & $\mathrm{a}$ & $0.024 \pm 0.002$ & c & $0.026 \pm 0.007$ & $\mathrm{a}$ & $0.133 \pm 0.011$ & $\mathrm{c}$ & $0.189 \pm 0.033$ & $\mathrm{a}$ \\
\hline \multirow[t]{6}{*}{120} & normal & $0.022 \pm 0.011$ & & $0.03 \pm 0.001$ & & $0.018 \pm 0.002$ & & $0.012 \pm 0.001$ & & $0.044 \pm 0$ & & $0.03 \pm 0.011$ & \\
\hline & normal + alcohol & $0.035 \pm 0$ & & $0.038 \pm 0.002$ & $\mathrm{~b}$ & $0.024 \pm 0.003$ & & $0.021 \pm 0$ & c & $0.08 \pm 0.009$ & $\mathrm{~b}$ & $0.022 \pm 0.005$ & \\
\hline & $\mathrm{As}_{2} \mathrm{O}_{3}$ & $0.066 \pm 0$ & & $0.092 \pm 0.003$ & & $0.042 \pm 0.001$ & & $0.035 \pm 0.005$ & & $0.372 \pm 0.012$ & & $0.296 \pm 0.015$ & \\
\hline & $\mathrm{As}_{2} \mathrm{O}_{3}+$ alcohol & $0.079 \pm 0$ & $\mathrm{c}$ & $0.098 \pm 0.001$ & & $0.046 \pm 0$ & $\mathrm{~b}$ & $0.039 \pm 0.003$ & & $0.416 \pm 0.009$ & $\mathrm{a}$ & $0.396 \pm 0.010$ & $\mathrm{c}$ \\
\hline & $\mathrm{As}_{2} \mathrm{O}_{3}+$ Ars Alb 6C & $0.047 \pm 0.001$ & $\mathrm{c}$ & $0.055 \pm 0.001$ & c & $0.03 \pm 0$ & c & $0.027 \pm 0.001$ & $\mathrm{~b}$ & $0.11 \pm 0.002$ & $\mathrm{c}$ & $0.12 \pm 0.006$ & $c$ \\
\hline & $\mathrm{As}_{2} \mathrm{O}_{3}+$ Ars Alb 30C & $0.045 \pm 0.002$ & $\mathrm{c}$ & $0.052 \pm 0.006$ & $\mathrm{c}$ & $0.025 \pm 0.001$ & c & $0.025 \pm 0.002$ & $\mathrm{~b}$ & $0.105 \pm 0.044$ & $\mathrm{c}$ & $0.118 \pm 0.054$ & $\mathrm{c}$ \\
\hline
\end{tabular}

$\mathrm{FI}=$ Fixation interval; prot. $=$ protection; $\mathrm{MDA}=$ malondialdehyde. ${ }^{\mathrm{a}} \mathrm{p}<0.05 ;{ }^{\mathrm{b}} \mathrm{p}<0.01 ;{ }^{\mathrm{c}} \mathrm{p}<0.001$. 
Table 2. Mean activities of AST, ALT and GSH in liver and spleen of mice treated with $\mathrm{As}_{2} \mathrm{O}_{3}, \mathrm{As}_{2} \mathrm{O}_{3}+$ alcohol, $\mathrm{As} \mathrm{O}_{2}+\mathrm{Ars} \mathrm{Alb} 6$, $\mathrm{As}_{2} \mathrm{O}_{3}+$ Ars Alb 30C and $\mathrm{As}_{2} \mathrm{O}_{3}+$ Ars Alb 6 by $\mathrm{As}_{2} \mathrm{O}_{3}+$ Ars Alb $6 \mathrm{C}$ and their normal positive and normal \pm alcohol negative controls

\begin{tabular}{|c|c|c|c|c|c|c|c|c|c|c|}
\hline \multirow{3}{*}{$\begin{array}{l}\text { FI } \\
\text { days }\end{array}$} & \multirow[t]{3}{*}{ Series } & \multicolumn{4}{|c|}{ AST, $\mathrm{nM} / \mathrm{mg}$ protein $/ \mathrm{min}$} & \multicolumn{3}{|c|}{$\mathrm{ALT}, \mathrm{nM} / \mathrm{mg}$ protein/min } & \multicolumn{2}{|l|}{$\mathrm{GSH}, \mathrm{nM} / \mathrm{mg}$ wet tissue } \\
\hline & & \multicolumn{2}{|l|}{ liver } & \multicolumn{2}{|l|}{ spleen } & liver & \multicolumn{2}{|l|}{ spleen } & liver & spleen \\
\hline & & activity $\pm \mathrm{SE}$ & prot. & activity $\pm \mathrm{SE}$ & prot. & activity $\pm \mathrm{SE}$ & activity $\pm \mathrm{SE}$ & prot. & activity $\pm \mathrm{SE}$ & activity $\pm \mathrm{SE}$ \\
\hline \multirow[t]{6}{*}{30} & normal & $0.014 \pm 0.001$ & & $0.011 \pm 0$ & & $0.006 \pm 0.001$ & $0.003 \pm 0$ & & $0.006 \pm 0.001$ & $0.005 \pm 0.001$ \\
\hline & normal + alcohol & $0.015 \pm 0.002$ & & $0.012 \pm 0.001$ & & $0.008 \pm 0.002$ & $0.007 \pm 0.001$ & $\mathrm{~b}$ & $0.003 \pm 0.001$ & $0.006 \pm 0.002$ \\
\hline & $\mathrm{As}_{2} \mathrm{O}_{3}$ & $0.03 \pm 0.001$ & & $0.025 \pm 0$ & & $0.012 \pm 0$ & $0.011 \pm 0.001$ & & $0.004 \pm 0$ & $0.004 \pm 0$ \\
\hline & $\mathrm{As}_{2} \mathrm{O}_{3}+$ alcohol & $0.033 \pm 0.001$ & & $0.027 \pm 0.001$ & & $0.016 \pm 0.002$ & $0.02 \pm 0.002$ & $\mathrm{~b}$ & $0.005 \pm 0$ & $0.004 \pm 0$ \\
\hline & $\mathrm{As}_{2} \mathrm{O}_{3}+$ Ars Alb 6C & $0.029 \pm 0.001$ & $\mathrm{a}$ & $0.027 \pm 0.001$ & & $0.016 \pm 0$ & $0.018 \pm 0$ & & $0.005 \pm 0.001$ & $0.005 \pm 0.001$ \\
\hline & $\mathrm{As}_{2} \mathrm{O}_{3}+$ Ars Alb 30C & $0.024 \pm 0.003$ & $\mathrm{a}$ & $0.019 \pm 0.001$ & c & $0.014 \pm 0.001$ & $0.004 \pm 0.001$ & $\mathrm{C}$ & $0.004 \pm 0.001$ & $0.004 \pm 0.001$ \\
\hline \multirow[t]{6}{*}{60} & normal & $0.02 \pm 0$ & & $0.008 \pm 0.001$ & & $0.008 \pm 0$ & $0.005 \pm 0.001$ & & $0.006 \pm 0.002$ & $0.007 \pm 0.001$ \\
\hline & normal + alcohol & $0.022 \pm 0.004$ & & $0.005 \pm 0.002$ & & $0.005 \pm 0.001 \mathrm{a}$ & $0.005 \pm 0.002$ & & $0.003 \pm 0.001$ & $0.005 \pm 0.001$ \\
\hline & $\mathrm{As}_{2} \mathrm{O}_{3}$ & $0.027 \pm 0.001$ & & $0.022 \pm 0.001$ & & $0.015 \pm 0$ & $0.015 \pm 0.001$ & & $0.002 \pm 0.001$ & $0.003 \pm 0$ \\
\hline & $\mathrm{As}_{2} \mathrm{O}_{3}+$ alcohol & $0.031 \pm 0.003$ & & $0.026 \pm 0.001$ & $\mathrm{a}$ & $0.019 \pm 0.001 \mathrm{~b}$ & $0.020 \pm 0$ & $\mathrm{~b}$ & $0.003 \pm 0.001$ & $0.004 \pm 0$ \\
\hline & $\mathrm{As}_{2} \mathrm{O}_{3}+$ Ars Alb 6C & $0.025 \pm 0.001$ & & $0.019 \pm 0.003$ & & $0.014 \pm 0.001 \mathrm{~b}$ & $0.009 \pm 0.001$ & $\mathrm{c}$ & $0.004 \pm 0.001$ & $0.005 \pm 0$ \\
\hline & $\mathrm{As}_{2} \mathrm{O}_{3}+$ Ars Alb 30C & $0.020 \pm 0.001$ & $\mathrm{~b}$ & $0.013 \pm 0.004$ & $\mathrm{a}$ & $0.012 \pm 0.002 \mathrm{a}$ & $0.007 \pm 0.002$ & $\mathrm{c}$ & $0.005 \pm 0.002$ & $0.005 \pm 0.002$ \\
\hline \multirow[t]{6}{*}{90} & normal & $0.011 \pm 0.001$ & & $0.016 \pm 0.003$ & & $0.005 \pm 0.004$ & $0.002 \pm 0.001$ & & $0.007 \pm 0.001$ & $0.009 \pm 0.001$ \\
\hline & normal + alcohol & $0.013 \pm 0$ & & $0.026 \pm 0.001$ & $\mathrm{a}$ & $0.006 \pm 0.001$ & $0.002 \pm 0$ & & $0.007 \pm 0.002$ & $0.008 \pm 0.001$ \\
\hline & $\mathrm{As}_{2} \mathrm{O}_{3}$ & $0.035 \pm 0.001$ & & $0.031 \pm 0.001$ & & $0.019 \pm 0.001$ & $0.02 \pm 0.001$ & & $0.001 \pm 0$ & $0.002 \pm 0.001$ \\
\hline & $\mathrm{As}_{2} \mathrm{O}_{3}+$ alcohol & $0.04 \pm 0.003$ & & $0.033 \pm 0.001$ & & $0.021 \pm 0$ & $0.021 \pm 0.003$ & & $0.002 \pm 0$ & $0.002 \pm 0$ \\
\hline & $\mathrm{As}_{2} \mathrm{O}_{3}+$ Ars Alb 6C & $0.020 \pm 0.002$ & c & $0.027 \pm 0.002$ & $\mathrm{a}$ & $0.008 \pm 0.001 \mathrm{c}$ & $0.008 \pm 0.004$ & $\mathrm{a}$ & $0.005 \pm 0.001 \mathrm{a}$ & $0.004 \pm 0.001$ \\
\hline & $\mathrm{As}_{2} \mathrm{O}_{3}+$ Ars Alb 30C & $0.018 \pm 0.003$ & $c$ & $0.023 \pm 0.001$ & c & $0.005 \pm 0.001 \mathrm{c}$ & $0.006 \pm 0$ & $\mathrm{~b}$ & $0.006 \pm 0.001 \mathrm{~b}$ & $0.006 \pm 0.001 \mathrm{~b}$ \\
\hline \multirow[t]{6}{*}{120} & normal & $0.012 \pm 0.001$ & & $0.011 \pm 0$ & & $0.005 \pm 0.002$ & $0.003 \pm 0$ & & $0.009 \pm 0.001$ & $0.009 \pm 0.002$ \\
\hline & normal + alcohol & $0.013 \pm 0.002$ & & $0.012 \pm 0.002$ & & $0.006 \pm 0.003$ & $0.006 \pm 0.001$ & $\mathrm{a}$ & $0.007 \pm 0.001$ & $0.008 \pm 0$ \\
\hline & $\mathrm{As}_{2} \mathrm{O}_{3}$ & $0.038 \pm 0.002$ & & $0.043 \pm 0$ & & $0.02 \pm 0$ & $0.024 \pm 0$ & & $0.001 \pm 0$ & $0.001 \pm 0.001$ \\
\hline & $\mathrm{As}_{2} \mathrm{O}_{3}+$ alcohol & $0.041 \pm 0$ & & $0.045 \pm 0.001$ & & $0.021 \pm 0.004$ & $0.028 \pm 0.001$ & $\mathrm{~b}$ & $0.001 \pm 0$ & $0.002 \pm 0$ \\
\hline & $\mathrm{As}_{2} \mathrm{O}_{3}+$ Ars Alb 6C & $0.016 \pm 0.005$ & $\mathrm{~b}$ & $0.023 \pm 0.002$ & c & $0.006 \pm 0.001 \mathrm{~b}$ & $0.007 \pm 0$ & $\mathrm{c}$ & $0.006 \pm 0.001 \mathrm{~b}$ & $0.006 \pm 0.001 \mathrm{~b}$ \\
\hline & $\mathrm{As}_{2} \mathrm{O}_{3}+$ Ars Alb 30C & $0.013 \pm 0$ & c & $0.019 \pm 0.001$ & c & $0.003 \pm 0.001 \mathrm{~b}$ & $0.004 \pm 0.001$ & c & $0.007 \pm 0.001 \mathrm{c}$ & $0.008 \pm 0.001 \mathrm{c}$ \\
\hline
\end{tabular}

that of the $\mathrm{As}_{2} \mathrm{O}_{3}+$ Ars Alb 6C-fed group. However, in spleen, an increase in ALT activity was observed at day 60 in the $\mathrm{As}_{2} \mathrm{O}_{3}+$ Ars Alb 30C-fed group, the reason of which was not quite clear. The activity again decreased at consecutive fixation intervals.

\section{GSH Content}

The increase in GSH content (table 2) was more pronounced in both liver and spleen tissues of $\mathrm{As}_{2} \mathrm{O}_{3}+$ Ars Alb 30C-fed mice than of $\mathrm{As}_{2} \mathrm{O}_{3}+$ Ars Alb 6C-fed mice, when compared to $\mathrm{As}_{2} \mathrm{O}_{3}$ + alcohol-fed series. However, this protective effect of the remedy was seen both in liver and spleen tissues only at longer fixation intervals.

\section{CAT and SDH Activities}

CAT and SDH activities were assayed only at longer fixation intervals, that is days 90 and 120 , when their activities were more detectable. CAT activity in $\mathrm{As}_{2} \mathrm{O}_{3}+$ alcohol-fed series was notably decreased in liver and spleen tissues at both fixation intervals when compared with normal controls (table 3). In both drug-fed series there was a significant recuperation in CAT activity. The efficacy shown by $\mathrm{As}_{2} \mathrm{O}_{3}+$ Ars Alb 30C in this regard was somewhat more pronounced than that of $\mathrm{As}_{2} \mathrm{O}_{3}+$ Ars Alb 6C.

A similar trend was also observed in the case of $\mathrm{SDH}$ (table 3). Here, both remedies were almost equally effective in rendering protection against arsenic trioxide-induced hepatic damage.

\section{Pathological Changes}

\section{Blood Sugar Content}

In $\mathrm{As}_{2} \mathrm{O}_{3}$ + alcohol-fed mice, an increase in blood sugar content (fig. 6) was observed at successive fixation intervals, the increase being significant at days 30 and 60 only. In $\mathrm{As}_{2} \mathrm{O}_{3}+\mathrm{Ars} \mathrm{Alb} 6 \mathrm{C}$-fed series, the blood sugar content was marked by successive waves of increase and 
Fig. 6. Column plot showing blood sugar concentration in different series of mice at different fixation intervals. ${ }^{* *} \mathrm{p}<0.01$; *** $\mathrm{p}<0.001$.

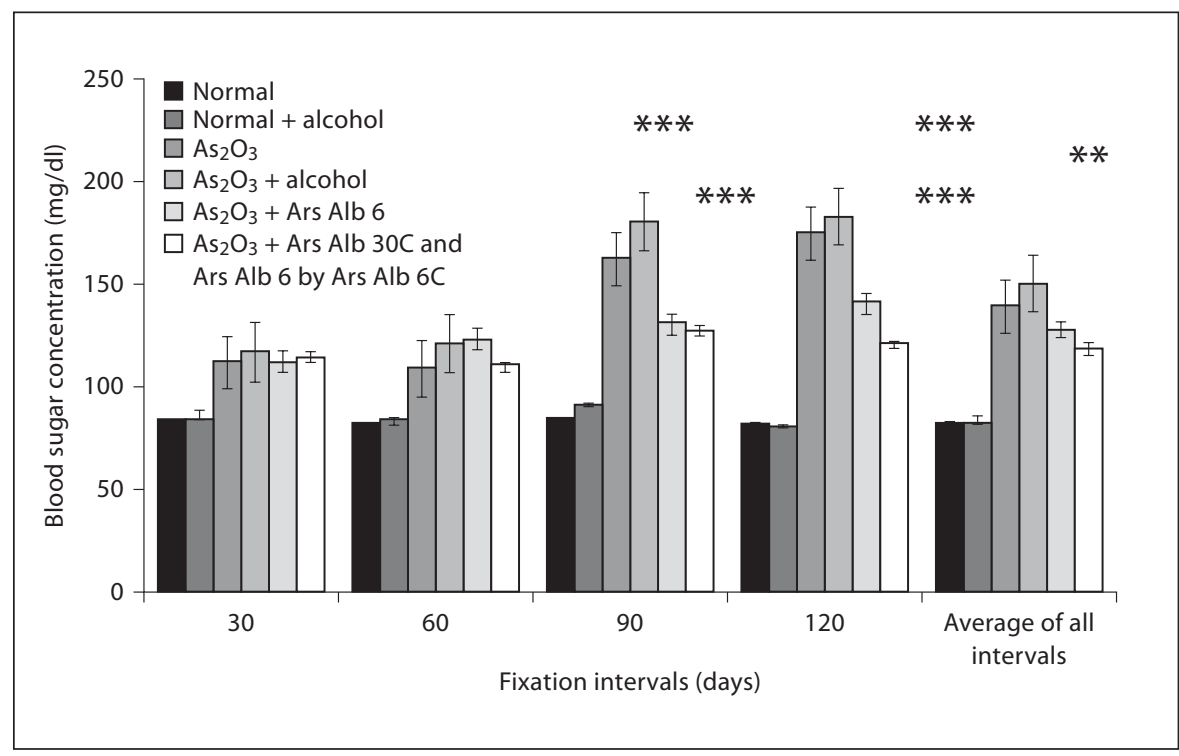

Table 3. Mean activities of SDH and CAT in liver and spleen of mice treated with $\mathrm{As}_{2} \mathrm{O}_{3}, \mathrm{As}_{2} \mathrm{O}_{3}+$ alcohol, $\mathrm{As}_{2} \mathrm{O}_{3}+\mathrm{Ars} \mathrm{Alb} 6$, $\mathrm{As}_{2} \mathrm{O}_{3}+$ Ars Alb 30C and $\mathrm{As}_{2} \mathrm{O}_{3}+$ Ars Alb 6 by $\mathrm{As}_{2} \mathrm{O}_{3}+$ Ars Alb 6C and their normal positive and normal + alcohol negative controls

\begin{tabular}{|c|c|c|c|c|c|c|c|c|}
\hline \multirow[t]{3}{*}{ Series } & \multicolumn{4}{|c|}{$\mathrm{SDH}, \mu \mathrm{mol} / \mathrm{mg}$ protein } & \multicolumn{4}{|c|}{$\mathrm{CAT}$, unit enzyme/mg protein } \\
\hline & \multicolumn{2}{|l|}{90 days } & \multicolumn{2}{|l|}{120 days } & \multicolumn{2}{|l|}{90 days } & \multicolumn{2}{|l|}{120 days } \\
\hline & liver & spleen & liver & spleen & liver & spleen & liver & spleen \\
\hline Normal & $530.00 \pm 1.58$ & $487.00 \pm 0.32$ & $550.00 \pm 1.26$ & $500.00 \pm 0.63$ & $8.80 \pm 0.003$ & $5.50 \pm 0.001$ & $8.70 \pm 0.001$ & $8.70 \pm 0.002$ \\
\hline Normal + alcohol & $541.00 \pm 1.26$ & $448.00 \pm 0.63$ & $557.00 \pm 0.63$ & $498.00 \pm 0.95$ & $8.60 \pm 0.001$ & $5.30 \pm 0.001$ & $8.50 \pm 0.001$ & $8.40 \pm 0.001$ \\
\hline $\mathrm{As}_{2} \mathrm{O}_{3}$ & $283.00 \pm 1.90$ & $272.00 \pm 1.58$ & $262.00 \pm 0.63$ & $261.00 \pm 1.26$ & $4.36 \pm 0.005$ & $2.30 \pm 0.001$ & $2.95 \pm 0.003$ & $1.86 \pm 0.002$ \\
\hline $\mathrm{As}_{2} \mathrm{O}_{3}+$ alcohol & $270.00 \pm 0.63$ & $256.00 \pm 0.95$ & $278.00 \pm 0.95$ & $230.00 \pm 1.30$ & $3.11 \pm 0.002$ & $1.90 \pm 0$ & $2.50 \pm 0.001$ & $1.40 \pm 0.001$ \\
\hline $\mathrm{As}_{2} \mathrm{O}_{3}+$ Ars Alb 6C & $386.00 \pm 0.95^{*}$ & $422.00 \pm 0.95^{*}$ & $480.00 \pm 1.26^{*}$ & $462.00 \pm 1.41^{*}$ & $5.3 \pm 0.003^{*}$ & $4.91 \pm 0.000^{*}$ & $5.83 \pm 0.001^{*}$ & $5.90 \pm 0.002^{*}$ \\
\hline $\mathrm{As}_{2} \mathrm{O}_{3}+$ Ars Alb 30C & $473.00 \pm 0.63^{*}$ & $437.00 \pm 1.26^{*}$ & $540.00 \pm 0.63^{*}$ & $478.00 \pm 1.38^{*}$ & $5.90 \pm 0.001^{*}$ & $5.33 \pm 0.003^{*}$ & $6.61 \pm 0.002^{*}$ & $6.10 \pm 0.002^{*}$ \\
\hline
\end{tabular}

${ }^{*} \mathrm{p}<0.001$.

decrease at corresponding fixation intervals. In $\mathrm{As}_{2} \mathrm{O}_{3}+$ Ars Alb 30C-fed series, a decrease in blood sugar content was generally revealed except at day 90 when a slight increase in blood sugar level was found. The protective potential of Ars Alb 30C appeared to be a little stronger than that of Ars Alb 6C.

\section{Blood Hemoglobin}

The hemoglobin content (fig. 7) was reduced in $\mathrm{As}_{2} \mathrm{O}_{3}$ + alcohol-fed mice compared to that of normal controls, while an increase in hemoglobin content was observed in both $\mathrm{As}_{2} \mathrm{O}_{3}+$ Ars Alb 6C-fed and $\mathrm{As}_{2} \mathrm{O}_{3}+$ Ars Alb 30Cfed mice, the increase being significant in $\mathrm{As}_{2} \mathrm{O}_{3}+$ Ars Alb 30C-fed series at day 90.

\section{Serum Estradiol and Testosterone Concentration}

In $\mathrm{As}_{2} \mathrm{O}_{3}$ - and $\mathrm{As}_{2} \mathrm{O}_{3}+$ alcohol-fed mice, a decrease in serum estrogen level (fig. 8) was obtained at days 90 and 120 compared to controls. Correspondingly, an increase in serum estrogen level was observed in both $\mathrm{As}_{2} \mathrm{O}_{3}+\mathrm{Ars}$ Alb 6C-fed and $\mathrm{As}_{2} \mathrm{O}_{3}+$ Ars Alb 30C-fed mice, the increase being slightly higher in case of Ars Alb $30 \mathrm{C}$ than in Ars Alb 6C.

Serum testosterone level (fig. 9) gradually decreased in $\mathrm{As}_{2} \mathrm{O}_{3}$ - and $\mathrm{As}_{2} \mathrm{O}_{3}+$ alcohol-fed mice, while in the drugfed series an increase in testosterone level was observed. Ars Alb 30C showed a slightly better efficacy than Ars Alb 6C. 
Fig. 7. Column plot showing hemoglobin levels in different series of mice at different fixation intervals.

Fig. 8. Column plot showing serum estrogen levels in different series of female mice at different fixation intervals.

Fig. 9. Column plot showing serum testosterone levels in different series of male mice at different fixation intervals.
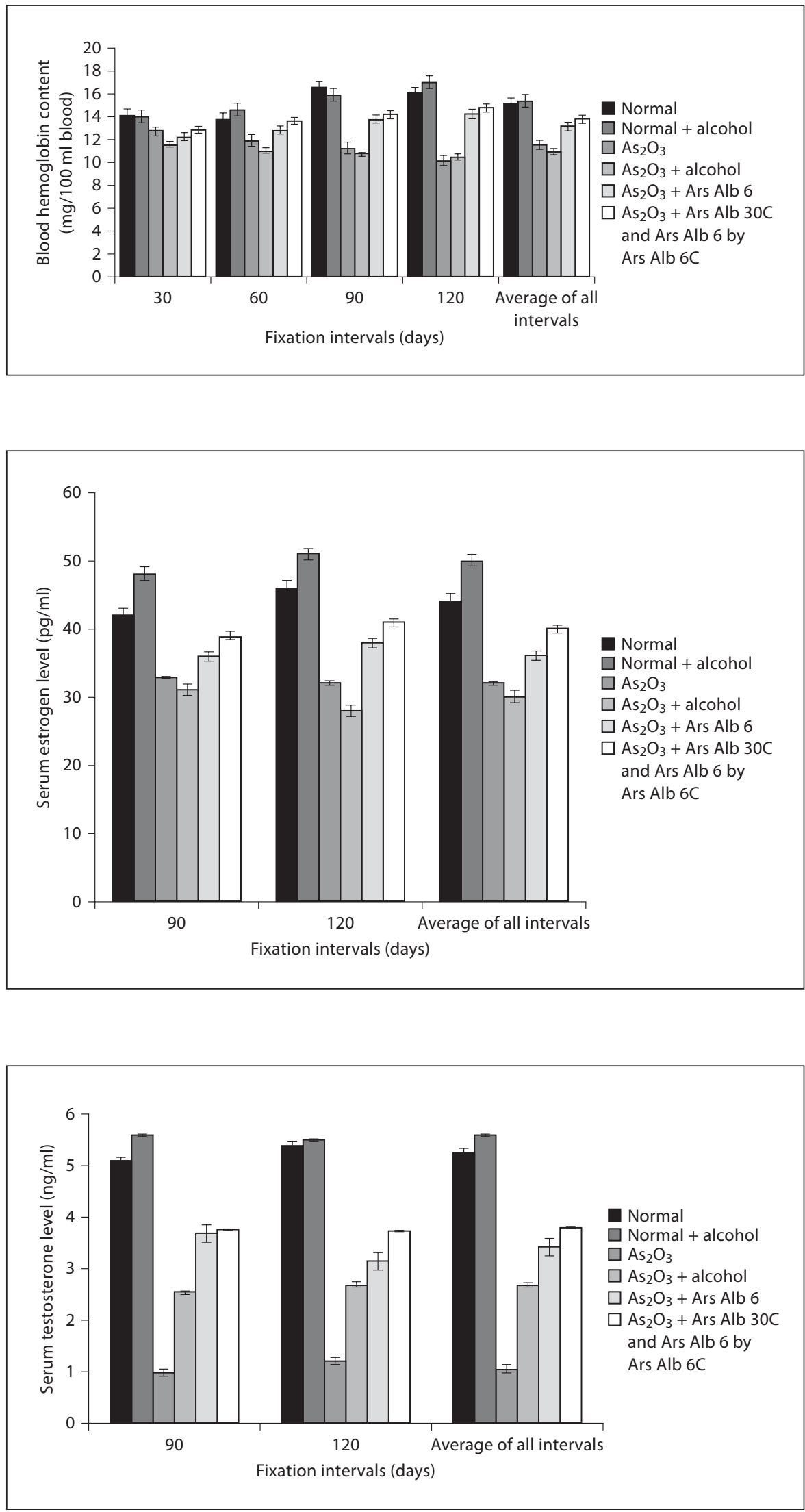


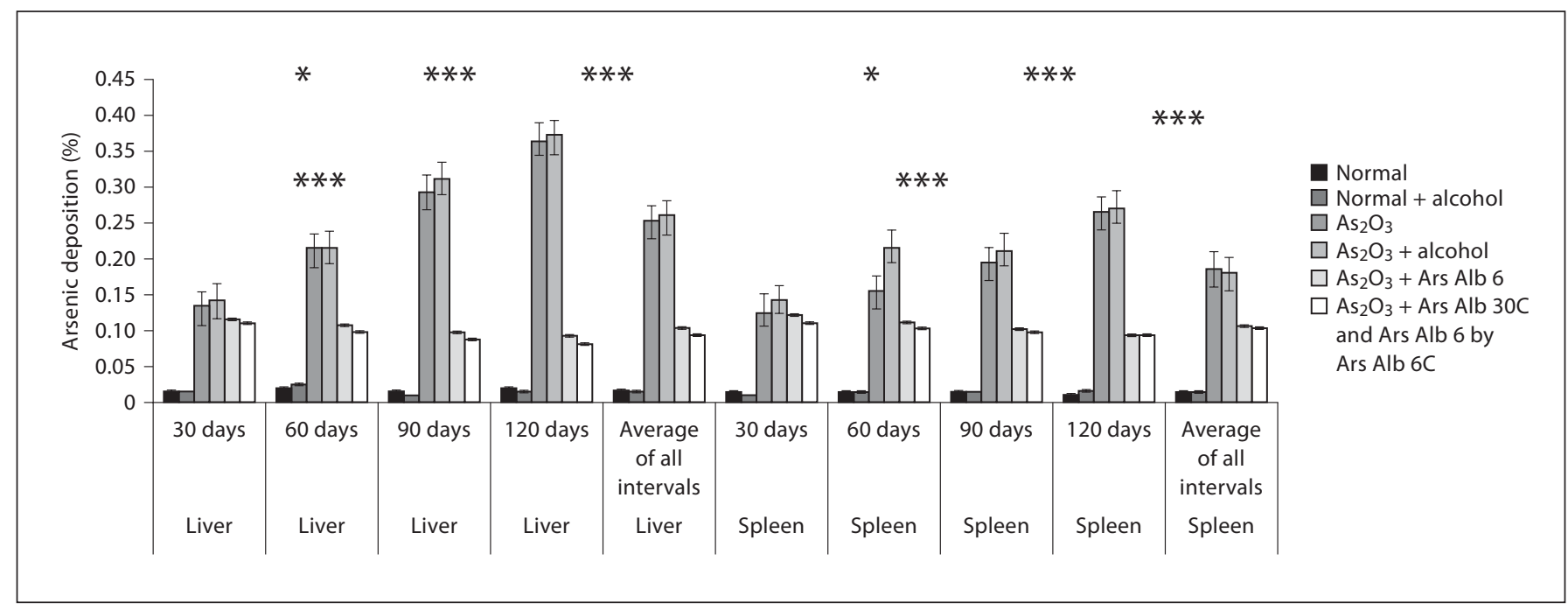

Fig. 10. Column plot showing arsenic deposition in liver and spleen of different series of mice at different fixation intervals. ${ }^{*} \mathrm{p}<0.05 ;{ }^{* * *} \mathrm{p}<0.001$.

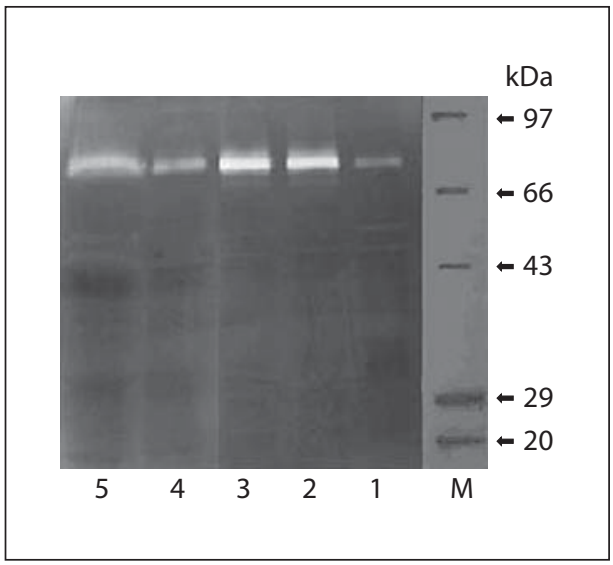

Fig. 11. Gelatin zymographic profile of the liver tissue of arsenic trioxide-injected and drug-fed mice at 90 days of fixation interval. Lane $1=$ Normal; lane $2=\mathrm{As}_{2} \mathrm{O}_{3}$; lane $3=\mathrm{As}_{2} \mathrm{O}_{3}+$ alcohol; lane $4=\mathrm{As}_{2} \mathrm{O}_{3}+$ Ars Alb 30C; lane $5=\mathrm{As}_{2} \mathrm{O}_{3}+$ Ars Alb 6C; $\mathrm{M}=$ molecular weight marker.

\section{Arsenic Content}

The $\mathrm{As}_{2} \mathrm{O}_{3}+$ alcohol-fed group showed a significant elevation in arsenic deposition (fig. 10) in both liver and spleen tissues when compared with that of the drug-fed group. However, in $\mathrm{As}_{2} \mathrm{O}_{3}+$ Ars Alb 30C-fed and $\mathrm{As}_{2} \mathrm{O}_{3}$ + Ars Alb 6C-fed series, the arsenic content in the above organs was strikingly lower, Ars Alb 30C showing slightly better efficacy than Ars Alb 6C.

Efficacy of Arsenicum Album against Arsenic Toxicity

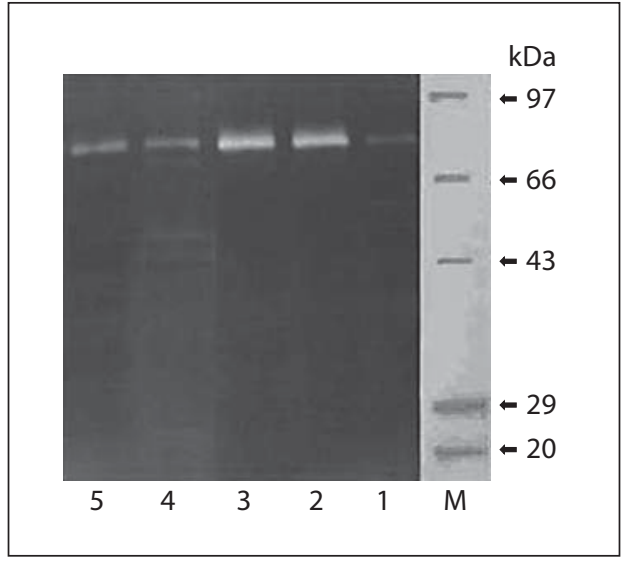

Fig. 12. Gelatin zymographic profile of the liver tissue of arsenic trioxide-injected and drug-fed mice at 120 days of fixation interval. Lane $1=$ Normal; lane $2=\mathrm{As}_{2} \mathrm{O}_{3}$; lane $3=\mathrm{As}_{2} \mathrm{O}_{3}+$ alcohol; lane $4=\mathrm{As}_{2} \mathrm{O}_{3}+$ Ars Alb 30C; lane $5=\mathrm{As}_{2} \mathrm{O}_{3}+$ Ars Alb 6C; $\mathrm{M}=$ molecular weight marker.

\section{Zymogram Profile for Protease Activity \\ (MMP Activity)}

At 90-day fixation interval, only 1 band was expressed near $77 \mathrm{kDa}$ in $\mathrm{As}_{2} \mathrm{O}_{3^{-}}$and $\mathrm{As}_{2} \mathrm{O}_{3}+$ alcohol-fed mice (fig. 11), which presumably belonged to MMP-2. In the drug-fed series, the expression of MMP-2 appeared to be somewhat lower than in the arsenic-intoxicated series. Similar results were also obtained at 120 days (fig. 12). A 
Table 4. One-way ANOVA for different cytogenetical parameters

\begin{tabular}{|c|c|c|c|c|c|c|c|c|c|c|c|c|}
\hline Source of variation & \multicolumn{3}{|c|}{ MI } & \multicolumn{3}{|c|}{$\mathrm{CA}$} & \multicolumn{3}{|c|}{ MN erythrocytes } & \multicolumn{3}{|c|}{ SHA } \\
\hline Within groups & 72 & & & 72 & & & 72 & & & 72 & & \\
\hline
\end{tabular}

Table 5. One-way ANOVA for different hepatic enzymes

\begin{tabular}{|c|c|c|c|c|c|c|c|c|c|c|c|c|}
\hline \multirow{2}{*}{$\begin{array}{l}\text { Source of } \\
\text { variation }\end{array}$} & \multicolumn{3}{|c|}{ AcP activity } & \multicolumn{3}{|c|}{ AlkP activity } & \multicolumn{3}{|c|}{ AST activity } & \multicolumn{3}{|c|}{ ALT activity } \\
\hline & $\mathrm{df}$ & $\mathrm{F}$ & sig. & $\mathrm{df}$ & $\mathrm{F}$ & sig. & $\mathrm{df}$ & $\mathrm{F}$ & sig. & $\mathrm{df}$ & $\mathrm{F}$ & sig. \\
\hline Within groups & 72 & & & 72 & & & 72 & & & 72 & & \\
\hline
\end{tabular}

\begin{tabular}{|c|c|c|c|c|c|c|c|c|c|c|c|c|}
\hline $\begin{array}{l}\text { Source of } \\
\text { variation }\end{array}$ & $\mathrm{df}$ & $\mathrm{F}$ & sig. & df & $\mathrm{F}$ & sig. & df & $\mathrm{F}$ & sig. & $\mathrm{df}$ & $\mathrm{F}$ & sig. \\
\hline Within groups & 72 & & & 72 & & & 72 & & & 72 & & \\
\hline
\end{tabular}

${ }^{*} \mathrm{p}<0.05$.

Table 6. One-way ANOVA for different spleen enzymes

\begin{tabular}{|c|c|c|c|c|c|c|c|c|c|c|c|c|}
\hline \multirow{2}{*}{$\begin{array}{l}\text { Source of } \\
\text { variation }\end{array}$} & \multicolumn{3}{|c|}{ AcP activity } & \multicolumn{3}{|c|}{ AlkP activity } & \multicolumn{3}{|c|}{ AST activity } & \multicolumn{3}{|c|}{ ALT activity } \\
\hline & $\mathrm{df}$ & $\mathrm{F}$ & sig. & df & $\mathrm{F}$ & sig. & df & $\mathrm{F}$ & sig. & df & $\mathrm{F}$ & sig. \\
\hline
\end{tabular}

\begin{tabular}{|c|c|c|c|c|c|c|c|c|c|c|c|c|}
\hline $\begin{array}{l}\text { Source of } \\
\text { variation }\end{array}$ & $\mathrm{df}$ & $\mathrm{F}$ & sig. & $\mathrm{df}$ & $\mathrm{F}$ & sig. & $\mathrm{df}$ & $\mathrm{F}$ & sig. & $\mathrm{df}$ & $\mathrm{F}$ & sig. \\
\hline
\end{tabular}

$$
{ }^{*} \mathrm{p}<0.05 \text {. }
$$


Table 7. One-way ANOVA for different blood parameters

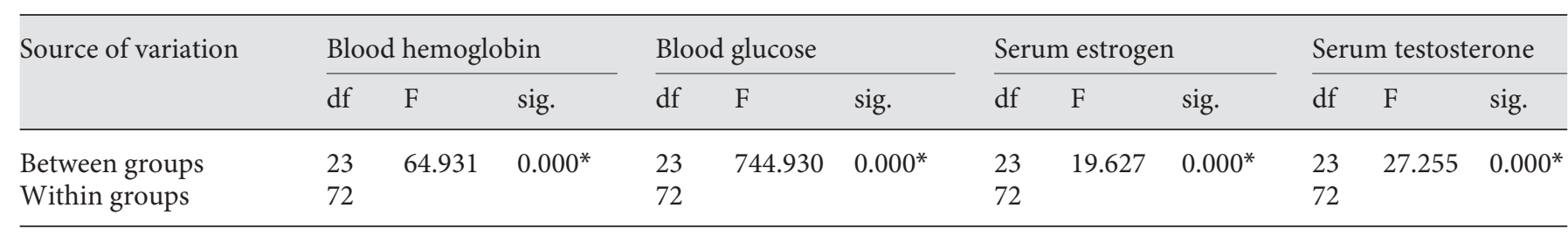

${ }^{*} \mathrm{p}<0.05$.

critical look would suggest that the expression of MMP-2 was slightly lower in Ars Alb 30C-fed mice than in Ars Alb $6 \mathrm{C}$-fed mice (see band-width), indicating the protective ability of Ars Alb 30C to be slightly more pronounced.

\section{Statistical Analysis of Data}

Data on the significance level between different series are provided in tables 1-3 for $t$ test values and in tables $4-8$ for one-way ANOVA, the tables being selfexplanatory.

\section{Discussion}

From a series of our earlier studies [13-18], it was evident that a single intraperitoneal injection of arsenic trioxide induced appreciable amount of toxicity in Swiss albino mice. Arsenic treatment in repeated doses induced a greater degree of toxicity in mice, as evidenced by elevation in the deposition of arsenic trioxide in both liver and spleen tissues. Cytogenetical parameters were studied to assess $\mathrm{As}_{2} \mathrm{O}_{3}$ toxicity at the genome level. Various forms of CA manifest either disorientation or breakage of DNA strands or some destructive changes in the protein matrix. SHA primarily point to disorientation of protein molecules. Incidentally, the ability of the potentized remedies, which hardly contained even a single molecule of the original drug substance, to repair/protect, could only be accomplished through suitably activating the inherent mechanism for repair of DNA and/or protein. Further, the extent of SHA and its repair/protection would indicate that the remedies could have positive influence on the gonadal tissues as well. The damage on sperm head morphology would also point to the risk of generation of distorted or defective offspring. Occurrence of $\mathrm{MN}$ in the arsenic-treated group could be due to their chronic effect
Table 8. One-way ANOVA for arsenic deposition in liver and spleen

\begin{tabular}{|c|c|c|c|c|c|c|}
\hline \multirow[t]{2}{*}{$\begin{array}{l}\text { Source of } \\
\text { variation }\end{array}$} & \multicolumn{3}{|c|}{$\begin{array}{l}\text { Arsenic deposition } \\
\text { in liver }\end{array}$} & \multicolumn{3}{|c|}{$\begin{array}{l}\text { Arsenic deposition } \\
\text { in spleen }\end{array}$} \\
\hline & df & $\mathrm{F}$ & sig. & df & $\mathrm{F}$ & sig. \\
\hline Between groups & 23 & 223.108 & $0.000^{*}$ & 23 & 123.164 & $0.000^{*}$ \\
\hline Within groups & 72 & & & 72 & & \\
\hline
\end{tabular}

on the chromosomes in different stages of cell cycle or due to their clastogenic and spindle-poisoning effect. Decrease in MI in arsenic-treated series of mice could be due to a decrease in the rate of cell division in the bone marrow cells.

Experimental studies have shown that exposure to arsenite results in LPO. Results of an epidemiological study of chronic exposure of Chinese residents to arsenic-containing drinking water indicated that although the activity for superoxide dismutase in blood did not differ significantly between the group exposed and the low-exposure group (control), the mean serum level of lipid peroxides was significantly higher among the high-exposure group [26]. Twelve weeks of arsenic exposure promote malondialdehyde production in both liver and brain samples [27]. Exposure to arsenic results in decreased GSH content. It was reported that after $1 \mathrm{~h}$ of exposure to arsenic (15.86 mg/kg body weight), the GSH concentration was significantly decreased in the liver of male Wistar rats [28]. In addition to a significant reduction in GSH levels, a marked elevation in MDA production may also contribute to arsenic-induced oxidative stress. The present study corroborates this fact and the levels of LPO were significantly higher in the arsenic- 
exposed group. Arsenic exposure increases oxidative damage to lipids and proteins and decreases the levels of antioxidants. The present study reported a significant reduction in the activities of antioxidant enzymes like CAT and GSH. The same results were also obtained in the case of SDH.

The liver appeared to be one of the major organs in which arsenic caused considerable damage, tissue necrosis and other histological as well as biochemical changes [13-18]. Liver damage as a consequence of arsenic poisoning has also been reported in human subjects [29]. The gradual increase in the activities of liver function enzymes like ALT, AST, AcP and AlkP after repeated injections of arsenic trioxide corroborates this view.

There was an elevation of blood glucose level in the arsenic trioxide-injected group compared to control, the increase being significant at $\mathrm{p}<0.001$ at day 90 . On the other hand, a gradual decrease in hemoglobin level was obtained along with a decrease in serum estrogen in the arsenic trioxide-treated group. This was accompanied by an increase in serum testosterone indicating that the toxicity could also influence changes in various metabolic processes including hormonal activities.

Arsenic has been classified as a group 1 carcinogen by the IARC [12] and it is known that carcinogens have a modulatory effect on metalloproteinase expression. A number of nonmatrix proteins are also known to be involved in inflammation, cell growth and differentiation [30]. MMP are a family of $\mathrm{Zn}^{2+}$ - and $\mathrm{Ca}^{2+}$-dependent endopeptidases secreted by both normal and transformed cells, capable of degrading collagenous and noncollagenous components of extracellular matrix [31,32]. The results of the present study revealed a high level of expression of metalloproteinase enzymes in $\mathrm{As}_{2} \mathrm{O}_{3}$ - as well as $\mathrm{As}_{2} \mathrm{O}_{3}+$ alcohol-treated mice. From the analysis of substrate specificity (gelatin) and molecular weight ( $97 \mathrm{kDa})$, it was suspected to be MMP-9, which showed increase in expression level in the arsenic-treated mice, but the activation was much lower in the drug-fed mice. This is in conformity with high levels of expression of metalloproteinases reported in pathological conditions such as wound healing, angiogenesis, tumor invasion, metastasis [33-36], arthritis, emphysema and apoptosis [37, 38].

The present investigation reflects the comparative efficacies of 2 microdoses of a potentized homeopathic drug, Ars Alb 6C and 30C, in amelioration of arsenic-induced toxicity. Reduction in the frequencies of CA, MN and SHA, decreased levels of AcP, AlkP, AST, ALT and LPO and increase in MI, and in activities of GSH, CAT and SDH were encountered in both the drug-fed series vis-à-vis controls, providing strong evidences to have reduced toxicity in the drug-fed mice. A critical look at the results would further indicate that Ars Alb 30C had a better protective potential than Ars Alb 6C. This apparently lends support to the contention that stronger dilutions of homeopathic remedies yield a slightly better result.

To our knowledge, attempts to ameliorate arsenic intoxication by this or any other homeopathic remedies have not been scientifically made by anyone else but us [13-18], neither in animal model or on human. However, the efficacy of Ars Alb 200 has been reported to have ameliorating effect on stray cases of arsenic intoxication in the homeopathic literature (http://www.geocities.com/ drratiram_sharma/). In the orthodox regimen, some antibiotics, chelators and vitamins tested had only a limited success in terms of their ability to remove arsenic from within the body or in their ability to ameliorate arsenicosis [29]. Further, except for vitamins, the other substances had their own toxic effects.

Single-dose injection of arsenic trioxide can produce lingering effect of one-time injury, whereas repeated injections of arsenic trioxide produce more pronounced effects of poisoning, leading to further detrimental consequences. Since there is a natural mechanism for the removal of arsenic, one-time injection of a sublethal dose only has an effect for a limited period. On the other hand, repeated injections would ensure that arsenic deposition was sustained in different organs for a longer period, facilitating studies on long-term effect, so that it can simulate the condition of natural chronic exposure to which animal and human subjects living in a contaminated zone are exposed. The positive ameliorative effect of homeopathic remedies against repeated injections in mice could therefore be more fruitfully extrapolated for implications of human use in high-risk arsenic-contaminated areas, where the majority of subjects is exposed to arsenic from various sources.

In our random survey made in certain high-risk arsenic localities, most volunteers showed some guiding symptoms particularly of hypertension and alimentary disorders including liver ailments and/or some skin symptoms typical of arsenicosis. Therefore, most victims had some sort of homeopathic guiding symptoms for the choice of Ars Alb as the remedy suitable for administration, though apparently using Ars Alb against arsenic toxicity may look like following the principle of isopathy. However, some care should be taken at the time of its human use for those subjects who do not show any external or other guiding symptoms, particularly in the case of children, though homeopathic remedies, per se, have no 
or minimal side effects. To avoid any possible drug proving effect that may arise on a prolonged repeated intake of potentized homeopathic remedies, periodic monitoring of arsenic content in urine or blood and intermittent withdrawal of the remedy are advisable as precautionary measures, since it is not known if Ars Alb also has any preventive action against arsenic toxicity.

How the ultra-low doses of the potentized remedy could bring about multiple changes in cytogenetical, enzymatic and pathological parameters is rather unclear at our present state of knowledge. Incidentally, KhudaBukhsh [39-41] has proposed a working hypothesis that one mechanism through which the potentized homeo- pathic drugs act could be regulation of expression of certain relevant genes. This explanation seems to be plausible because all biomarkers tested are regulated by specific genetic regulatory mechanisms, and without involvement of these regulatory mechanisms, such positive results could not have been achieved.

\section{Acknowledgement}

This work was financially supported through a research grant from Boiron Lab, Lyon, France, to A.R. Khuda-Bukhsh.

\section{References}

1 Rahman M, Tondel M, Ahmad SA: Hypertension and arsenic exposure in Bangladesh. Hypertension 1999;33:74-78.

$\checkmark 2$ Engel RR, Smith AH: Arsenic in drinking water and mortality from vascular disease: an ecologic analysis in 30 counties in the United States. Arch Environ Health 1994;49: 418-427.

-3 Wu MM, Kuo TL, Hwang YH, Chen CJ: Dose-response relation between arsenic concentration in well water and mortality from cancers and vascular diseases. Am J Epidemiol 1989;130:1123-1132.

$4 \mathrm{Hu}$ H: Exposure to metals. Prim Care 2000; 27:983-996.

5 Chen CJ, Wang CJ: Ecological correlation between arsenic level in well water and ageadjusted mortality from malignant neoplasms. Cancer Res 1990;50:5470-5474.

6 International Programme on Chemical Safety: Inorganic Arsenic Compounds Other than Arsine. Health and Safety Guide No. 70. Geneva, World Health Organization, 1992.

7 International Programme on Chemical Safety: Environmental Health Criteria Document 224: Arsenic and Arsenic Compounds. Geneva, World Health Organization, 2001.

8 International Agency for Research on Cancer: Summaries and Evaluations: Arsenic and Arsenic Compounds. Lyon, International Agency for Research on Cancer, 1987.

9 Department for Environment Food and Rural Affairs, Environment Agency: Contaminants in Soil: Collation of Toxicological Data and Intake Values for Humans. Arsenic. Bristol, Environment Agency, 2002.

10 Tchounwou PB, Wilson BA, Ishaque A: Important considerations in the development of public health advisories for arsenic and arsenic containing compounds in drinking water. Rev Environ Health 1999;14:1-19.
11 National Academy of Sciences: Arsenic. Washington, National Academy of Sciences, 1977.

12 Overall evaluation of carcinogenicity: an update of IARC monographs. IARC Monogr Eval Carcinog Risks Hum 1989;47:1-42.

-13 Mitra K, Kundu SN, Khuda-Bukhsh AR: Efficacy of a potentized homeopathic drug (arsenicum album-30) in reducing toxic effects produced by arsenic trioxide in mice: I. On the rate of accumulation of arsenic in certain vital organs. Complement Ther Med 1998;6: 178-184.

14 Mitra K, Kundu SN, Khuda-Bukhsh AR: Efficacy of a potentized homeopathic drug (arsenicum album-30) in reducing toxic effects produced by arsenic trioxide in mice: II. On alterations of body weight, tissue weight and total protein. Complement Ther Med 1999;7: 24-34.

15 Kundu SN, Mitra K, Khuda-Bukhsh AR: Efficacy of a potentized homeopathic drug (arsenicum album-30) in reducing cytotoxic effects produced by arsenic trioxide in mice: III. Enzymatic changes and recovery of tissue damage in liver. Complement Ther Med 2000;8:76-81.

16 Kundu SN, Mitra K, Khuda-Bukhsh AR: Efficacy of a potentized homeopathic drug (arsenicum album-30) in reducing cytotoxic effects produced by arsenic trioxide in mice: IV. Pathological changes, protein profiles and content of DNA and RNA. Complement Ther Med 2000;8:157-175.

17 Datta S, Mallick P, Khuda-Bukhsh AR: Efficacy of a potentized homeopathic drug (arsenicum album-30) in reducing genotoxic effects produced by arsenic trioxide in mice: comparative studies of pre-, post- and combined pre- and post-oral administration and comparative efficacy of two microdoses. Complement Ther Med 1999;7:62-75.
18 Mallick P, Chakrabarti Mallick J, Guha B, Khuda-Bukhsh AR: Ameliorating effect of microdoses of a potentized homeopathic drug, arsenicum album, on arsenic induced toxicity in mice. BMC Complement Altern Med 2003;3:1-19.

19 Pathak S, Das JK, Biswas SJ, Khuda-Bukhsh AR: Protective potentials of a potentized homeopathic drug, Lycopodium-30, in ameliorating azo dye induced hepatocarcinogenesis in mice. Mol Cell Biochem 2006;258: 121-131.

20 Biswas SJ, Pathak S, Khuda-Bukhsh AR: Assessment of the genotoxic and cytotoxic potential of an antiepileptic drug phenobarbital, in mice: a time course study. Mutat Res 2004;563:1-11.

21 Pathak S, Bhattacharjee N, Das JK, Choudhury SC, Karmakar SR, Banerjee P, Paul S, Banerjee A, Khuda-Bukhsh AR: Supportive evidence for the anticancerous potential of alternative medicine against hepatocarcinogenesis in mice. Forsch Komplement Med (2006) 2007;14:148-156.

22 Billings PC, Habres JM, Liao DC, Tuttle SW: Human fibroblasts contain a proteolytic activity, which is inhibited by the BowmanBirk protease inhibitor. Cancer Res 1991;51: 5539-5543.

23 Locke J: The determination of eight elements in human liver tissue by flame atomic absorption spectrometry in sulphuric acid solution. Anal Chem Acta 1979;104:225-231.

24 Nurenberg WH: Voltametric trace analysis in ecological chemistry of toxic metals. Pure Appl Chem 1982;54:853-878.

25 Fisher RA, Yates F: Statistical Tables for Biological, Agricultural and Medical Research. Edinburgh, Oliver and Boyd, 1963. 
26 Pi JB, Yamauchi H, Kumagai Y: Evidence for induction of oxidative stress caused by chronic exposure of Chinese residents to arsenic contained in drinking water. Environ Health Perspect 2002;110:331-336.

27 Flora SJS: Arsenic-induced oxidative stress and its reversibility following combined administration of $\mathrm{N}$-acetylcysteine and meso 2,3-dimercaptosuccinic acid in rats. Clin Exp Pharmacol Physiol 1999;26:865-869.

28 Maiti S, Chatterjee AK: Effects on levels of glutathione and some related enzymes in tissues after an acute arsenic exposure in rats and their relationship to dietary protein deficiency. Arch Toxicol 2001;75:531-537.

29 Guha Mazumder DN, Das Gupta J, Santra A, Pal A, Ghose A, Sarkar S, Chattopadhaya N, Chakraborti D: Non-cancer effects of chronic arsenicosis with special reference to liver damage; in Aberthy CO, Calderon RL, Chappel WR (eds): Arsenic: Exposure and Health Effects. London, Chapman and Hall, 1997, pp 113-123.
30 Sternlicht MD, Werb Z: How matrix metalloproteases regulate cell behaviour. Annu Rev Cell Dev Biol 2001;17:463-516.

31 Liotta LA, Steeg PS, Stetler-Stevenson WG Cancer metastasis and angiogenesis: an imbalance of positive and negative regulation. Cell 1991;64:327-336.

32 Matrisian LM: Metalloproteinases and their inhibitors in matrix remodeling (review). Trends Genet 1990;6:121-125.

33 Woessner JF Jr: Matrix metalloproteinases and their inhibitors in connective tissue remodeling. FASEB J 1991;5:2145-2154.

34 Lee AY, Akers KT, Collier M, Li L, Eisen AZ, Seltzer JL: Intracellular activation of gelatinase A (72-kDa type IV collagenase) by normal fibroblasts. Proc Natl Acad Sci USA 1997;94:4424-4429.

35 Seltzer JL, Lee AY, Akers KT, Sudbeck B, Southon EA, Wayner EA, Eisen AZ: Activation of 72-kDa type IV collagenase/gelatinase by normal fibroblasts in collagen lattices is mediated by integrin receptors but is not related to lattice contraction. Exp Cell Res 1994;213:365-374.
36 Birkedal-Hansen H: Proteolytic remodeling of extracellular matrix. Curr Opin Cell Biol 1995;7:728-735.

37 Ray JM, Stetler-Stevenson WG: The role of matrix metalloproteases and their inhibitors in tissue invasion, metastasis and angiogenesis. Eur Respir J 1994;7:2062-2072.

38 Wang Z, Juttermann R, Soloway PD: TIMP-2 is required for efficient activation of proMMP-2 in vivo. J Biol Chem 2000;275: 26411-26415.

39 Khuda-Bukhsh AR: Potentized homeopathic drugs act through regulation of gene expression: a hypothesis to explain their mechanism and pathways of action in vivo. Complement Ther Med 1997;5:43-46.

-40 Khuda-Bukhsh AR: Towards understanding molecular mechanisms of action of homeopathic drugs: an overview. Mol Cell Biochem 2003;253:339-345.

41 Khuda-Bukhsh AR: Laboratory research in homeopathy: pro. Integr Cancer Ther 2006; 5:320-332. 